\title{
PENERAPAN FUZZY LOGIC UNTUK MENINGKATKAN DERAJAT KEBENARAN DETEKSI PADA ALAT BANTU BUTA WARNA BERBASIS SENSOR OPTIK
}

\author{
Johan Iskandar') dan Dian Kartika Utami ${ }^{2}$ ) \\ 1, 2) Sekolah Vokasi, Universitas Pakuan, Bogor, Indonesia \\ Corresponding Author: johan_iskandar@unpak.ac.id
}

Article history: received 4 September 2018; revised 20 September 2018; accepted 1 Desember 2018

\begin{abstract}
Abstrak
Prototipe deteksi warna berbasis Arduino dan sensor warna TCS3200 telah berhasil dikembangkan. Prototipe ini dibangun dengan menerapkan logika fuzzy untuk meningkatkan akurasi pembacaan warna berdasarkan tingkat keanggotaan $(\mu(x))$. Metode yang digunakan adalah mengubah ruang warna RGB (merah, hijau, biru) menjadi ruang warna HSV (Hue, Saturation, Value). Dari ruang warna HSV, nilai Hue diambil sebagai variabel independen dalam membuat kurva segmentasi warna dan $\mu$ (x). Bentuk keluaran dari prototipe adalah suara dengan informasi warna yang terdeteksi. Untuk mendapatkan jarak optimal dari deteksi warna, sensor ditempatkan pada jarak $1 \mathrm{~cm}, 2, \mathrm{~cm}$ dan $3 \mathrm{~cm}$ dari objek. Dari hasil pengujian, akurasi yang diperoleh pada jarak $1 \mathrm{~cm}$ adalah 100\%, jarak 2 adalah $94.7 \%$ dan $89.4 \%$ pada jarak $3 \mathrm{~cm}$. Oleh karena itu dapat disimpulkan bahwa jarak ideal untuk mengukur prototipe adalah $1 \mathrm{~cm}$.
\end{abstract}

Kata Kunci: Arduino, TCS3200, RGB, HSV, fuzzy logic

\begin{abstract}
Arduino-based color detection prototype and TCS3200 color sensor have been successfully developed. This prototype was built by applying fuzzy logic to improve the accuracy of color readings based on the degree of membership $(\mu(x))$. The method used is to transform the RGB color space (red, green, blue) to the HSV color space (Hue, Saturation, Value). From the HSV color space the Hue value is taken as the independent variable in making the color segmentation curve and $\mu(x)$. The output form of the prototype is a sound with detected color information. To get the optimal distance of color detection, the sensor is placed at a distance of $1 \mathrm{~cm}, 2, \mathrm{~cm}$ and $3 \mathrm{~cm}$ from the object. From the test results, obtained accuracy at a distance of $1 \mathrm{~cm}$ is $100 \%$, distance 2 is $94.7 \%$ and $89.4 \%$ at a distance of $3 \mathrm{~cm}$. Therefore it can be concluded that the ideal distance for measuring prototype is $1 \mathrm{~cm}$.
\end{abstract}

Keywords : Arduino, TCS3200, RGB, HSV, fuzzy logic

\section{Pendahuluan}

Buta warna merupakan suatu keadaan dimana mata seseorang tidak mampu untuk menangkap warna tertentu. Buta warna mengakibatkan penderitanya berkemungkinan mengalami kesulitan dalam berbagai hal dalam kehidupan sehari-hari. Hal tersebut dikarenakan dalam kehidupan seringkali warna diasosiasikan dengan hal tertentu atau difungsikan sebagai penanda. Sebagai contoh, digunakannya warna sebagai penanda dalam rambu-rambu lalu lintas, lampu lalu lintas, penanda blok pada suatu lokasi, dan lain-lain. Alat bantu pendeteksi warna dibuat memanfaatkan sifat optik bahan dan prinsip refektansi ketika beberapa objek dengan warna berbeda diberikan cahaya putih dengan perlakuan yang sama maka setiap objek tersebut akan memantulkan cahaya dengan panjang gelombang yang berbeda-beda, hal inilah yang akan digunakan sebagai informasi dasar dalam penentuan warna dalam alat yang akan dibuat $[1,2]$. 
Dua property cahaya yang paling jelas dapat langsung dideskripsikan dengan teori gelombang untuk cahaya: intensitas dan warna. Intensitas cahaya merupakan energi yang dibawanya per satuan waktu, dan sebanding dengan kuadrat amplitudo gelombang. Warna cahaya berhubungan dengan panjang gelombang atau frekuensi cahaya tersebut. Cahaya tampak adalah cahaya yang sensitif bagi mata kita, terdapat pada kisaran $400 \mathrm{~nm}$ sampai $750 \mathrm{~nm}$. Kisaran ini dikenal sebagai spektrum tampak seperti pada Gambar 1, dan di dalamnya terdapat warna - warna dari ungu sampai merah. Cahaya dengan panjang gelombang yang lebih pendek dari 400nm disebut ultraviolet (UV), dan cahaya dengan panjang gelombang lebih besar dari 750 $\mathrm{nm}$ disebut infra merah (IR). Walaupun mata manusia tidak sensitif terhadap UV dan IR, beberapa jenis film fotografi bereaksi terhadap cahaya - cahaya ini [3].

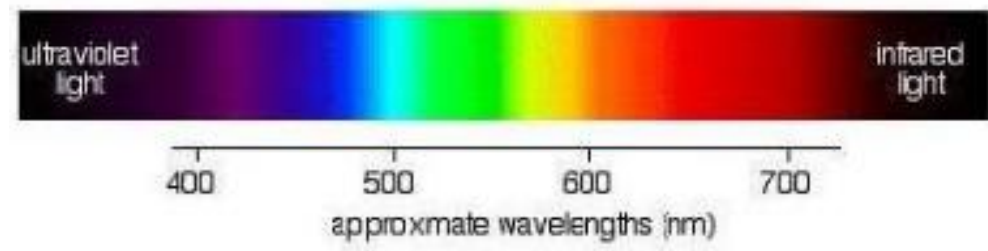

Gambar 1. Spektrum cahaya tampak

Penelitian yang dilakukan oleh peneliti sebelumnya adalah membuat google glass (kacamata pintar) [4] untuk menanggulangi kekurangan penglihatan warna akibat penggunaan Handphoe yang berlebihan

Penelitian-penelitian yang sudah dilakukan belum menggunakan sensitifitas sensor, yaitu menggunakan fuzzy logic sebagai sensitifitas nilai baca sensor dengan menggunakan citra Hue, Saturation, Value (HSV). Pengolahan citra dilakukan dengan mengubah citra warna RGB Red, Green, Blue (RGB) menjadi HSV. Segmentasi dilakukan dengan ruang warna fuzzy, artinya dilakukan berdasarkan fungsi keanggotaan kelompok-kelompok warna pada hue citra Ishihara. Akan tetapi pengelompokan batas warna dilakukan berdasarkan nilai-nilai hue pada citra Ishihara dengan ruang warna HSV. Agar bisa mensegmentasi pola semua citra Ishihara yang digunakan untuk pengujian digunakan nilai batas hue 0.31 dan 244. Kemudian setelah diperoleh hasil segmentasi untuk masing-masing batas warna, selanjutnya dipilih hasil segmentasi yang dominan (luasan paling besar). Segmentasi dominan dihilangkan, sehingga hanya diperoleh pola citra Ishihara. Kemudian pola citra Ishihara yang tersegmentasi dikembalikan lagi ke ruang warna RGB.

Logika Fuzzy merupakan seuatu logika yang memiliki nilai kekaburan atau kesamaran (fuzzyness) antara benar atau salah. Dalam teori logika fuzzy suatu nilai bias bernilai benar atau salah secara bersama. Namun berapa besar keberadaan dan kesalahan suatu tergantung pada bobot keanggotaan yang dimilikinya. Logika fuzzy memiliki derajat keanggotaan dalam rentang 0 hingga 1. Derajat keanggotaan 0 (FALSE) artinya nilai bukan merupakan anggota himpunan dan 1 (TRUE) berarti nilai tersebut adalah anggota himpunan. Logika fuzzy digunakan untuk menterjemahkan suatu besaran yang diekspresikan menggunakan bahasa (linguistic), misalkan besaran kecepatan laju kendaraan yang diekspresikan dengan pelan, agak cepat, cepat, dan sangat cepat. Logika fuzzy menunjukan sejauh mana suatu nilai itu benar dan sejauh mana suatu nilai itu salah $[5,6]$. Logika fuzzy adalah suatu cara yang tepat untuk memetakan suatu ruang input kedalam suatu ruang output, mempunyai nilai kontinyu. Fuzzy dinyatakan dalam derajat dari suatu keanggotaan dan derajat dari kebenaran. Oleh sebab itu sesuatu dapat dikatakan sebagian benar dan sebagian salah pada waktu yang sama $[7,8]$.

\section{Fungsi Keanggotaan Fuzzy}

Fungsi keanggotaan adalah suatu kurva yang menunjukkan pemetaan titiktitik input data ke dalam nilai keanggotaannya (sering juga disebut dengan derajat keanggotaan) yang memiliki interval antara 0 sampai 1 . Salah satu cara yang dapat digunakan untuk memperoleh nilai keanggotaan adalah dengan melalui pendekatan fungsi keanggotaan seperti fungsi keanggotaan segitiga dan fungsi keanggotaan trapezium [9]. 
a. Fungsi keanggotaan Segitiga

Fungsi keanggotaan segitiga ditandai oleh adanya 3 (tiga) parameter $\{a, b, c\}$ yang akan menentukan koordinat $x$ dari tiga sudut. Kurva ini pada dasarnya merupakan gabungan antara dua garis (linier). Adapun untuk bentuk segitiga ini adalah dengan menggunakan Persamaan 1:

$$
\mu[x]= \begin{cases}0 & x \leq a \text { atau } x \geq c \\ (x-a) /(b-a) & a \leq x \leq b \\ (c-x) /(c-b) & b \leq x \leq c\end{cases}
$$

Grafik fungsi keanggotaannya dapat dilihat pada Gambar 2.

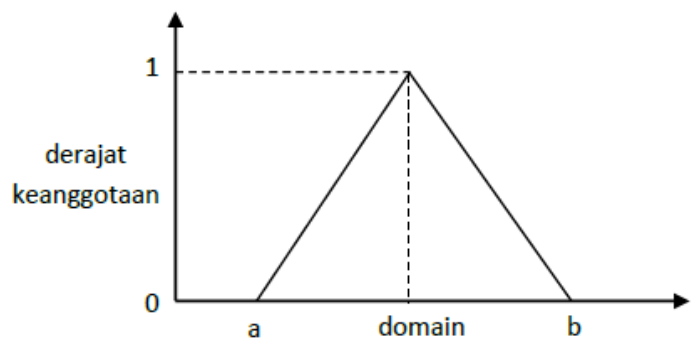

Gambar 2. Grafik fungsi keanggotaan segitiga

b. Fungsi keanggotaan trapesium

Kurva trapesium pada dasarnya seperti bentuk segitiga, hanya saja ada beberapa titik yang memiliki nilai keanggotaan 1. Adapun untuk kurva trapesium ini adalah dengan menggunakan Persamaan 2:

$$
\mu[x]= \begin{cases}0 & x \leq a \text { atau } x \geq d \\ (x-a) /(b-a) & a \leq x \leq b \\ 1 & b \leq x \leq c \\ (d-x) /(d-c) & c \leq x \leq d\end{cases}
$$

Gambar grafik fungsi keanggotaannya dapat dilihat pada Gambar 3.

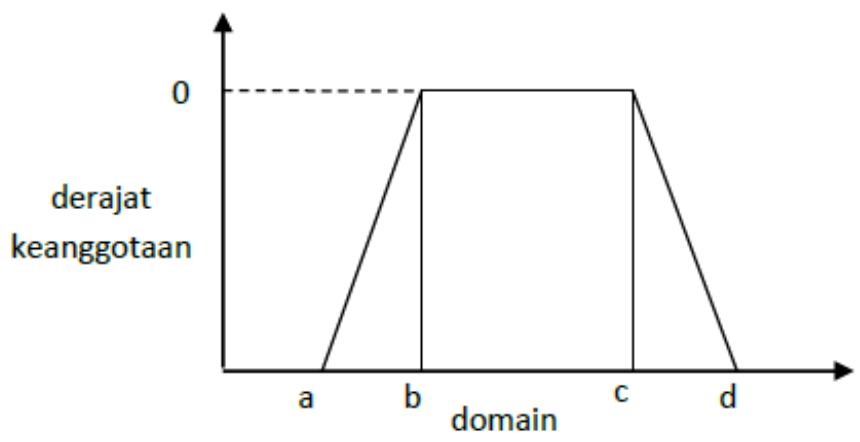

Gambar 3. Grafik fungsi keanggotaan trapesium

Tujuan dari penelitian ini adalah membuat alat bantu deteksi warna dengan menerapkan logika fuzzy guna menghasilkan detektor warna yang lebih tepat. 


\section{Metode Penelitian}

Dalam penelitian ini metode yang diterapkan adalah hardware programming yang dibagi menjadi tiga bagian perancangan yaitu:

\subsection{Perancangan sistem mekanik}

Dalam tahap ini dilakukan perancangan bentuk fisik dari prototipe yang akan dibuat yang terdiri dari penentuan posisi sensor, peletakan aktuator dan komponen elektronika lainnya sehingga diperoleh gambaran dari bentuk dan ukuran prototipe dalam tiga dimensi. Software yang akan digunakan dalam perancangan 3D ini adalah autocad, kemudian hasilnya akan dicetak menggunakan printer 3D.

\subsection{Perancangan sistem elektronik}

Perancangan rangkaian elektronik dibagi menjadi dua tahapan yaitu tahap simulasi dan tahap pembuatan printed circuit board (PCB). Pada tahap simulasi betujuan untuk menekan biaya serta menghindari try and error jika langsung dibuat rangkaian sebenarnya pada PCB. Software yang digunakan dalam simulasi ini adalah Proteus seri ke 8.6. Pada tahap yang kedua jika dalam simulasi telah berhasil dengan indikator tidak ditemukannya komponen yang tidak bekerja maka akan dibuat rangkaian skematik PCB dengan menggunakan software eagle agar dihasilkan dimensi PCB yang optimal karena hal ini akan berpengaruh ke ukuran prototipe secara keseluruhan serta biaya yang akan dikeluarkan.

\subsection{Tahap Pemrograman}

Sebelum tahap ini dilakukan, terlebih dahulu sistem mekanik yang telah dibuat diintegrasikan dengan sistem elektronik yang telah dirancang. Dalam memproses setiap sinyal atau data hasil pembacaaan sensor akan dilakukan oleh sebuah unit mikrokontroller. Setiap eksekusi yang dilakukan oleh aktuator selalu berdasarkan kondisi yang ditentukan pada program yang ditanam pada unit ini. Oleh karena terlebih dahulu dilakukan pengujian awal pada prototipe secara manual yaitu dengan tanpa dikendalikan oleh mikrokontroller yang bertujuan untuk mendapatkan kondisikondisi serta variabel yang akan dimasukkan pada program dalam bentuk persamaan. Bahasa pemrograman yang digunakan dalam penelitian ini adalah bahasa $\mathrm{C}$.

\section{Hasil dan Pembahasan}

Hasil yang diperoleh dari penelitian ini adalah berupa prototipe sebagai alat bantu mengenali warna dengan menerapkan logika fuzzy agar pendeteksian warna lebih tepat. Dalam Tabel 1 disajikan data hasil pengujian prototipe terhadap beragam warna yang divalidasi di situs internet color-blindness.com dengan memasukkan nilai Hue yang terbaca sensor seperti tampak pada Gambar 4 [10]. 
KOMPUTASI (Jurnal Ilmiah Ilmu Komputer dan Matematika)

Vol.16, No.1, Januari 2019, Hal. $195-202$

p-ISSN: 1693-7554, e-ISSN: 2654-3990

https://journal.unpak.ac.id/index.php/komputasi

Tabel 1. Hasil pengujian prototipe terhadap warna dasar pada dimensi Hue

\begin{tabular}{|c|c|c|c|c|c|}
\hline \multirow[t]{2}{*}{ No } & \multirow[t]{2}{*}{ Warna yang diuji } & \multicolumn{3}{|c|}{ Pengukuran Prototipe } & \multirow{2}{*}{$\begin{array}{l}\text { Warna di } \\
\text { color- } \\
\text { blindness.co } \\
m\end{array}$} \\
\hline & & $\begin{array}{l}\text { Jarak } \\
\text { pengukuran }\end{array}$ & Hue terukur & $\begin{array}{l}\text { Warna } \\
\text { terdeteksi }\end{array}$ & \\
\hline \multirow{3}{*}{1} & & $1 \mathrm{~cm}$ & 326 & Merah & Merah \\
\hline & & $2 \mathrm{~cm}$ & 320 & Merah & Merah \\
\hline & & $3 \mathrm{~cm}$ & 312 & Merah & Merah \\
\hline \multirow{3}{*}{2} & & $1 \mathrm{~cm}$ & 326 & Merah & Merah \\
\hline & & $2 \mathrm{~cm}$ & 320 & Merah & Merah \\
\hline & & $3 \mathrm{~cm}$ & 318 & Merah & Merah \\
\hline \multirow{3}{*}{3} & & $1 \mathrm{~cm}$ & 335 & Merah & Merah \\
\hline & & $2 \mathrm{~cm}$ & 331 & Merah & Merah \\
\hline & & $3 \mathrm{~cm}$ & 322 & Merah & Merah \\
\hline \multirow{3}{*}{4} & & $1 \mathrm{~cm}$ & 322 & Merah & Merah \\
\hline & & $2 \mathrm{~cm}$ & 314 & Merah & Merah \\
\hline & & $3 \mathrm{~cm}$ & 309 & Ungu & Merah \\
\hline \multirow{3}{*}{5} & & $1 \mathrm{~cm}$ & 25 & Oranye & Oranye \\
\hline & & $2 \mathrm{~cm}$ & 14 & Merah & Oranye \\
\hline & & $3 \mathrm{~cm}$ & 11 & Merah & Merah \\
\hline \multirow{3}{*}{6} & & $1 \mathrm{~cm}$ & 68 & Kuning & Kuning \\
\hline & & $2 \mathrm{~cm}$ & 46 & Kuning & Kuning \\
\hline & & $3 \mathrm{~cm}$ & 19 & Oranye & Oranye \\
\hline \multirow{3}{*}{7} & & $1 \mathrm{~cm}$ & 62 & Kuning & Kuning \\
\hline & & $2 \mathrm{~cm}$ & 31 & Oranye & Oranye \\
\hline & & $3 \mathrm{~cm}$ & 18 & Oranye & Merah \\
\hline \multirow{3}{*}{8} & & $1 \mathrm{~cm}$ & 137 & $\mathrm{Hijau}$ & Hijau \\
\hline & & $2 \mathrm{~cm}$ & 134 & Hijau & Hijau \\
\hline & & $3 \mathrm{~cm}$ & 127 & Hijau & Hijau \\
\hline \multirow{3}{*}{9} & & $1 \mathrm{~cm}$ & 104 & Hijau & Hijau \\
\hline & & $2 \mathrm{~cm}$ & 115 & Hijau & Hijau \\
\hline & & $3 \mathrm{~cm}$ & 54 & Kuning & Kuning \\
\hline \multirow{3}{*}{10} & & $1 \mathrm{~cm}$ & 168 & Biru muda & Biru muda \\
\hline & & $2 \mathrm{~cm}$ & 189 & Biru muda & Biru muda \\
\hline & & $3 \mathrm{~cm}$ & 226 & Biru & Biru \\
\hline \multirow{3}{*}{11} & & $1 \mathrm{~cm}$ & 192 & Biru muda & Biru Muda \\
\hline & & $2 \mathrm{~cm}$ & 204 & Biru muda & Biru Muda \\
\hline & & $3 \mathrm{~cm}$ & 220 & Biru & Biru \\
\hline \multirow{3}{*}{12} & & $1 \mathrm{~cm}$ & 225 & Biru & Biru \\
\hline & & $2 \mathrm{~cm}$ & 265 & Ungu & Ungu \\
\hline & & $3 \mathrm{~cm}$ & 276 & Ungu & Ungu \\
\hline \multirow{3}{*}{13} & & $1 \mathrm{~cm}$ & 246 & Biru & Biru \\
\hline & & $2 \mathrm{~cm}$ & 276 & Ungu & Ungu \\
\hline & & $3 \mathrm{~cm}$ & 269 & Ungu & Ungu \\
\hline
\end{tabular}

Color Name \& Hue
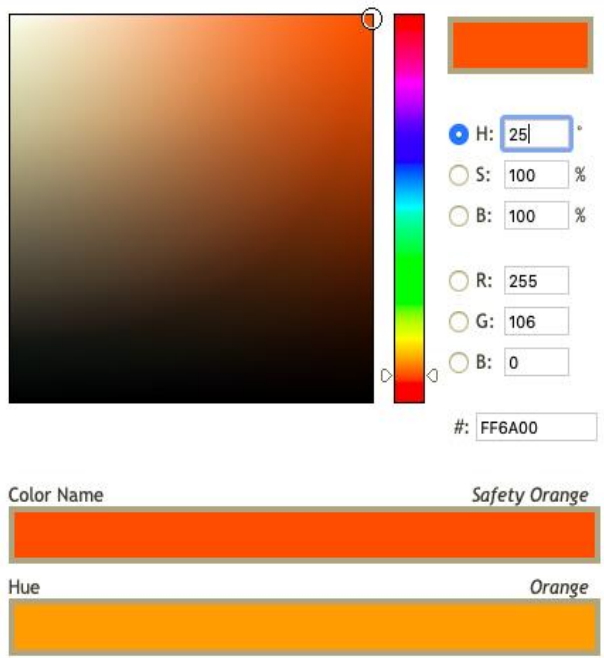
Gambar 4. Pengujian nilai Hue dan Warna di color-blindness.com

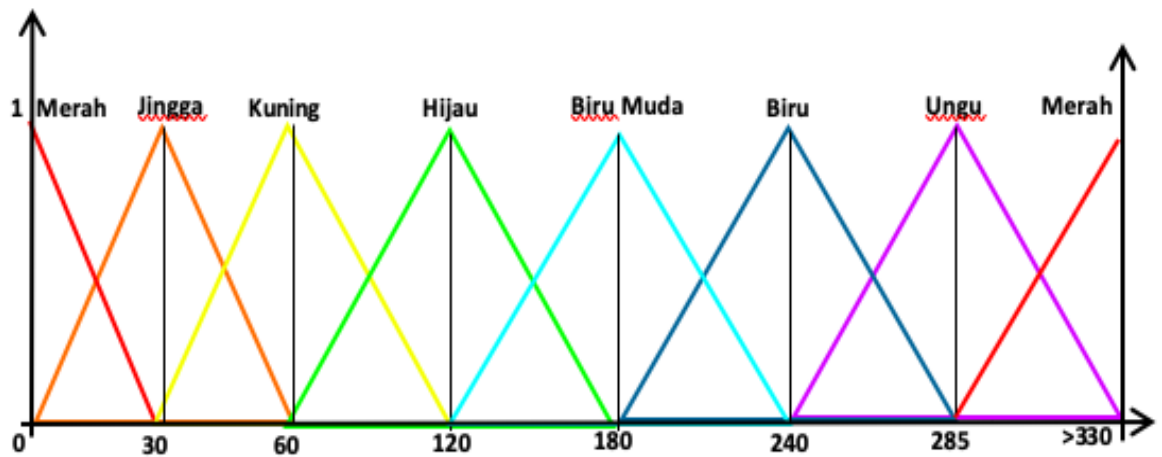

Gambar 5. Dimensi Hue

Hasil klasifikasi warna pada Tabel 1 diperoleh berdasarkan dimensi warna pada Gambar 5 dimana sumbu $\mathrm{x}$ menyatakan Dimensi Hue, dan sumbu y adalah derajat keanggotaan $\mu(x)$. Dalam menyatakan warna sebuah objek, prototipe melakukan operasi dengan menghitung nilai derajat keanggotaan fuzzy $((x))$ dari nilai Hue yang terbaca oleh sensor dengan persamaan 3 dan persamaan $4[11,12]$.

Representasi Linear Naik :

$$
\mu[x]=(x-a) /(b-a) ; a \leq x \leq b .
$$

Representasi Linear Turun:

$$
\mu[x]=(b-x) /(b-a) ; a \leq x \leq b .
$$

Berikut ini dijelaskan bagaiamana No. 6 (jarak ukur $2 \mathrm{~cm}$ ) pada Tabel 1 dengan nilai Hue 46 dan prototipe menyatakan warna kuning. Pada dasarnya nilai hue 46 merujuk pada Gambar 5 memiliki representasi derajat keanggotan logika antara 0 (FASE) dan 1 (TRUE). Berikut ini proses perhitungan derajat keanggotaan oleh prototipe:

Diketahui : $x=46, a=30, b=60$

Representasi linear naik dari persamaan (3):

$\mu(x)=(x-a) /(b-a)$

$=(46-30) /(60-30)$

$=16 / 30$

$=0.53$

Representasi linear turun dari persamaan (4):

$\mu(x)=(b-x) /(b-a)$

$=(60-46) /(60-30)$

$=14 / 30$

$=0.47$

Berdasarkan perhitungan derajat keanggotaan yang dilakukan diatas, maka diperoleh derajat keanggotaan 0.53 untuk warna kuning dan 0.47 untuk warna oranye. Berdasarkan perhitungan derajat keanggotaan warna Kuning memiliki nilai yang lebih besar dibandingkan dengan warna oranye. Warna kuning menunjukkan nilai derajat keanggotaan mendekati 1 , sehingga prototipe akan memutuskan objek yang dideteksi adalah berwarna kuning. Jika hasil perhitungan $(x)$ dinyatakan dalam sebuah kurva akan tampak seperti pada Gambar 6. 


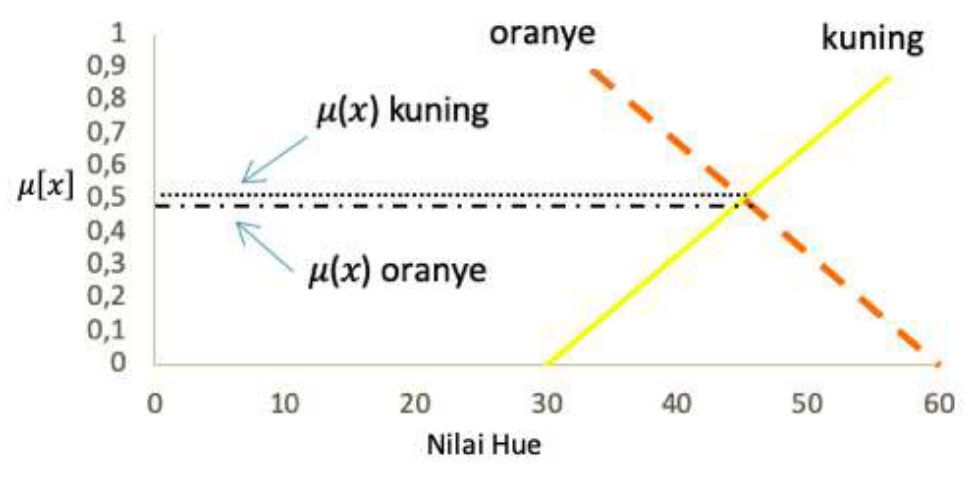

Gambar 6. Kurva derajat keanggotaan terhadap nilai Hue

Berdasarkan Tabel 1, ketepatan pengukuruan warna yang terdeteksi oleh prototipe mencapai $100 \%$ pada jarak ukur $1 \mathrm{~cm}, 94.7 \%$ pada jarak $2 \mathrm{~cm}$ dan $89.4 \%$ pada jarak $3 \mathrm{~cm}$. Oleh karena itu dapat disimpulkan jarak ideal pengukuran dengan prototipe yaitu $1 \mathrm{~cm}$.

Prinsip kerja prototipe yang dibuat diringkas dalam flowchart pada Gambar 7. Dimana hasil akhirnya adalah prototipe mengeluarkan suara melalui speaker atau headphone berupa warna yang terdeteksi.

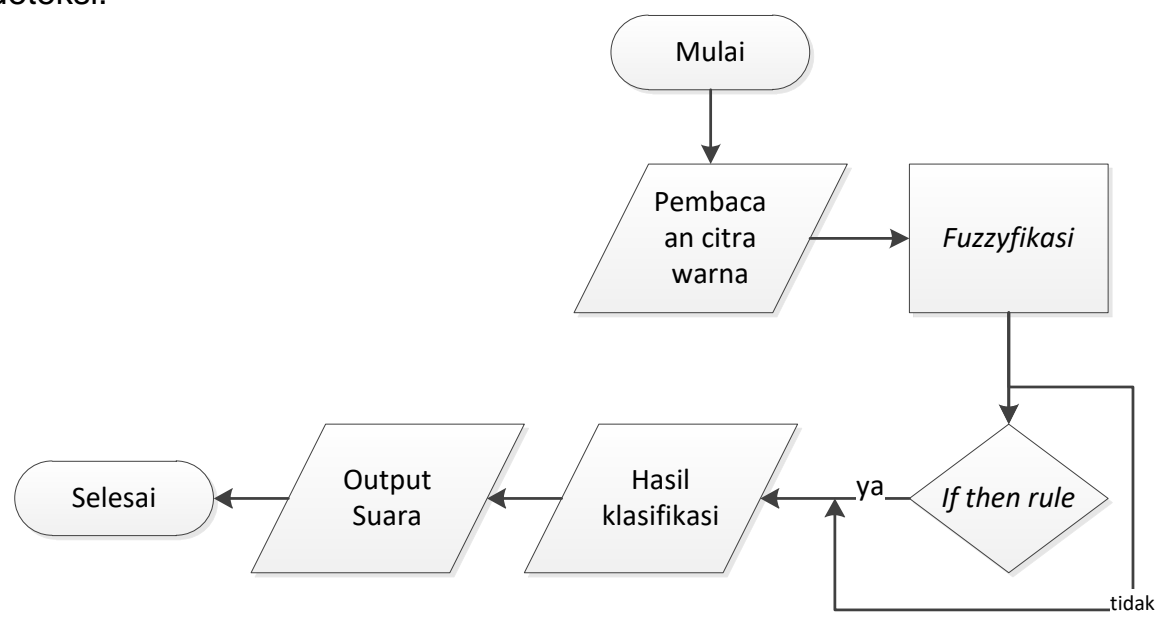

Gambar 7. Flowchart cara kerja prototipe

\section{Kesimpulan}

Jarak optimal pendeteksian warna oleh prototipe adalah $1 \mathrm{~cm}$ dengan ketepatan $100 \%$. Ketika jarak pengukuran diperbesar dari $1 \mathrm{~cm}$ menjadi $2 \mathrm{~cm}$ dan $3 \mathrm{~cm}$, terjadi penurunan ketepatan akibat pengaruh cahaya dari luar yang masuk ke probe sensor, sehingga akan mempengaruhi pembacaan oleh sensor TCS3200.

Prinsip kerja dari perototipe ini yaitu mendeteksi warna dalah ruang warna RGB kemudian dikonversi ke ruang warna HSV. Pada dasarnya setiap warna akan diproyeksikan ke dalam dua nilai Hue sehingga akan menghasilkan dua derajat keanggotaan. Warna akhir yang ditampilkan ditentukan berdasarkan derajat keanggotaan yang lebih mendekati 1. 


\section{Referensi}

[1] Randy, V.D., Ernawati \& Desi, A. 2014. Aplikasi Tes Buta Warna dengan Metode Ishihara pada Smartphone Android. Jurnal Pseudocode, 1(1):2355-5920.

[2] Widianingsih, R, Kridalaksana, AH \& Hakim, AR. 2010. Aplikasi Tes Buta Warna Dengan Metode Ishihara Berbasis Komputer. Jurnal Informatika Mulawarman, 5(1):3641.

[3] Saiful, W, Kusworo, A \& Hernowo, D. 2013. Rancang Bangun Alat Deteksi Warna untuk Membantu Penderita Buta Warna berbasis Mikrokontroller AVR ATMega16. Youngster Journal Physics, 1(4):133-142.

[4] George, L, Michael, S \& Martin, E. 2017. OmniColor-A Smart Glasses App to Support Colorblind People. International Journal of Interactive Mobile Technology, 11(5):161177.

[5] Nasution \& Helfi. 2012. Implementasi Logika Fuzzy pada Sistem Kecerdasan Buatan. Jurnal ELKHA, 4(2):4-8.

[6] Ayeman, J, Ons, Z \& Mohamed, AH. 2018. Hardware Implementation of a Fuzzy Logic Controller for a Hybrid Wind-Solar System in an Isolated Site. International Journal of Photoenergy, 2018:1-16.

[7] Kusumadewi, S., Purnomo, H. 2004. Aplikasi Logika Fuzzy Untuk Pendukung Keputusan. Graha IImu. Yogyakarta.

[8] Pawan W \& Ahmad, SN. 2017. Fuzzy Logic Implementation of Photo Catalytic Sensor. Journal International Robotics and Automation, 2(3):2-5.

[9] Sutojo, Mulyanto \& Suhartono, V. 2011. Kecerdasan Buatan. Andi Ouset. Yogyakarta.

[10] Colblindor. 2018. Color Name \& Hue. https://www.color-blindness.com/color-namehue/. 15 November 2019 (15:34).

[11] Thamotharan, S. 2016. A Study on Multi Server Fuzzy Queuing Model in Triangular and Trapezoidal Fuzzy Numbers Using $\alpha$ Cuts. International Journal of Science and Research, 5(1):226 - 230.

[12] Amit, K, Neetu \& Abhinav, B. 2012. A New Computational Method for Solving Fully Fuzzy Linear Systems of Triangular Fuzzy Numbers. Journal Fuzzy Information and Engineering, 4(1):63-73. 